\title{
Capsule Commentary on Njeru et al., Diabetes Mellitus Management Among Patients with Limited English Proficiency: a Systematic Review and Meta-analysis
}

\author{
Amy Cunningham, $\mathrm{PhD}, \mathrm{MPH}$ \\ Department of Family and Community Medicine, Thomas Jefferson University, Philadelphia, PA, USA.
}

J Gen Intern Med 33(6):947

DOI: $10.1007 / \mathrm{s} 11606-018-4422-\mathrm{x}$

(c) Society of General Internal Medicine 2018

$\mathrm{L}$ imited English proficiency (LEP) is associated with numerous health disparities, including poorer glycemic control in LEP patients with diabetes. ${ }^{1}$ In this issue, Njeru et al. ${ }^{2}$ report findings from a systematic review and meta-analysis of diabetes self-management education (DSME) interventions in LEP populations. In their meta-analysis, DSME interventions were associated with a significant lower hemoglobin $\mathrm{A}_{1 \mathrm{c}}(-0.84 \%$ [95\% CI, -0.97 to -0.71$\left.]\right)$ than usual care. Interventions lasting less than 6 months and using in-person delivery were more likely to demonstrate improvements in hemoglobin $\mathrm{A}_{1 \mathrm{c}}$. Improvements in selfefficacy, quality of life, and several other measures were also reported.

This systematic review and meta-analysis is the first to examine the impact of DSME in LEP populations, and includes a sizable number of articles. The clinically significant reduction in hemoglobin $A_{1 c}$ and positive effects on selfefficacy and quality of life are encouraging findings that are consistent with prior meta-analyses of DSME's effect in the general population ${ }^{3}$ and in racial and ethnic minority groups. ${ }^{4}$ The study also has several notable limitations. Nearly half of the included studies were non-randomized designs. Additionally, none of the interventions enrolled exclusively LEP participants, and for nearly half of included studies, LEP participation rates were "inferred" from demographics tables or the article text. Furthermore, nearly all studies (94\%) offered LEP accommodations, such as language-concordant staff or translated materials, but it was unclear which accommodations were most helpful to participants. Finally, the overall heterogeneity of the interventions, including delivery methods and intensity, precludes conclusions about the most effective DSME designs for LEP populations.
The findings from Njeru et al. ${ }^{2}$ suggest fruitful avenues for future research. Overall, the LEP population in the USA is very linguistically and culturally heterogeneous with substantial variations in country of origin, education level, and socioeconomic status. ${ }^{5}$ Development and evaluation of DSME for specific LEP sub-populations would strengthen the evidence for DSME's impact on LEP participants and clarify the most effective intervention components for different groups. For clinicians and health educators, understanding their local LEP populations and working with community partners is critical to designing linguistically and culturally appropriate DSME to meet the needs of this vulnerable population.

Corresponding Author: Amy Cunningham, $\mathrm{PhD}, \mathrm{MPH}$; Department of Family and Community Medicine Thomas Jefferson University, Philadelphia, PA, USA (e-mail: Amy.Cunningham@jefferson.edu).

\section{Compliance with Ethical Standards:}

Conflict of Interest: The author declares that she does not have a conflict of interest.

\section{REFERENCES}

1. Choi S, Lee JA, Rush E. Ethnic and language disparities in diabetes care among California residents. Ethn Dis. 2011;21(2):183-9.

2. Njeru JW, Wieland ML, Kwete G, Tan EM, Breitkopf CR, Agunwamba AA, Prokop LJ, Murad MH. Diabetes mellitus management among patients with limited english proficiency: a systematic review and meta-analysis. J Gen Intern Med. https://doi.org/10.1007/s11606017-4237-1.

3. Steinsbekk A, Rygg L, Lisulo M, Rise MB, Fretheim A. Group based diabetes self-management education compared to routine treatment for people with type 2 diabetes mellitus. A systematic review with metaanalysis. BMC Health Serv Res. 2012;12(1):213.

4. Ricci-Cabello I, Ruiz-Pérez I, Rojas-García A, Pastor G, RodriguezBarranco M, Gonçalves DC. Characteristics and effectiveness of diabetes self-management educational programs targeted to racial/ethnic minority groups: a systematic review, meta-analysis and meta-regression. BMC Endocr Disord. 2014;14(1):60.

5. Pandya C, Batalova J, McHugh M. Limited English proficient individuals in the United States: number, share, growth, and linguistic diversity [Internet]. Washington (DC): Migration Policy Institute; 2011 [cited 2017 Nov 28]. Available from: http://www.migrationinformation.org/integration/LEPdatabrief.pdf. 